Chemosphere, vol. 181, 2017, pp. 518-529.

\title{
Amitraz changes NE, DA and 5- HT biosynthesis and metabolism mediated by alterations in estradiol content in CNS of male rats.
}

del Pino Sans, Javier, Moyano-Cires Ivanof, Paula, Ruiz, Matilde, Anadón Baselga, María José, Díaz, María José, García, José Manuel, Labajo González, Elena y Frejo Moya, María Teresa.

Cita:

del Pino Sans, Javier, Moyano-Cires Ivanof, Paula, Ruiz, Matilde, Anadón Baselga, María José, Díaz, María José, García, José Manuel, Labajo González, Elena y Frejo Moya, María Teresa (2017). Amitraz changes NE, DA and 5-HT biosynthesis and metabolism mediated by alterations in estradiol content in CNS of male rats. Chemosphere, 181, 518-529.

Dirección estable: https://www.aacademica.org/elenalabajogonzalez/36 ARK: https://n2t.net/ark:/13683/pcQr/EPy

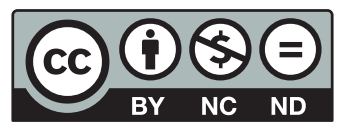




\title{
Amitraz changes NE, DA and 5-HT biosynthesis and metabolism mediated by alterations in estradiol content in CNS of male rats
}

\author{
Javier del Pino ${ }^{\mathrm{a},}{ }^{*}, 1$, Paula Moyano ${ }^{\mathrm{b}, 1}$, Matilde Ruiz ${ }^{\mathrm{b}}$, María José Anadón ${ }^{\mathrm{b}}$, \\ María Jesús Díaz a, José Manuel García b, Elena Labajo-González b , María Teresa Frejo a \\ a Department of Toxicology and Pharmacology, Veterinary School, Complutense University of Madrid, 28040 Madrid, Spain \\ ${ }^{\mathrm{b}}$ Department of Toxicology and Legal Medicine, Medical School, Complutense University of Madrid, 28041 Madrid, Spain
}

\section{H I G H L I G H T S}

- Amitraz did not inhibit MAO at 20,50 and $80 \mathrm{mg} / \mathrm{kg}$ doses.

- Amitraz altered MAO, COMT, DBH, TH and TRH expression and TH and TRH activity.

- Enzymes' expression alteration was partially mediated by estradiol levels alteration.

- Amitraz alter monoaminergic systems by estradiol levels disruption.

\section{A R T I C L E I N F O}

\section{Article history:}

Received 29 January 2017

Received in revised form

20 April 2017

Accepted 23 April 2017

Available online 26 April 2017

Handling Editor: A. Gies

\section{Keywords}

Amitraz

Male rats

Neurotoxicity

Monoaminergic neurotransmitters

Estradiol

\begin{abstract}
A B S T R A C T
Amitraz is a formamidine insecticide/acaricide that alters different neurotransmitters levels, among other neurotoxic effects. Oral amitraz exposure $(20,50$ and $80 \mathrm{mg} / \mathrm{kg}$ bw, 5 days) has been reported to increase serotonin (5-HT), norepinephrine (NE) and dopamine (DA) content and to decrease their metabolites and turnover rates in the male rat brain, particularly in the striatum, prefrontal cortex, and hippocampus. However, the mechanisms by which these alterations are produced are not completely understood. One possibility is that amitraz monoamine oxidase (MAO) inhibition could mediate these effects. Alternatively, it alters serum concentrations of sex steroids that regulate the enzymes responsible for these neurotransmitters synthesis and metabolism. Thus, alterations in sex steroids in the brain could also mediate the observed effects. To test these hypothesis regarding possible mechanisms, we treated male rats with 20,50 and $80 \mathrm{mg} / \mathrm{kg}$ bw for 5 days and then isolated tissue from striatum, prefrontal cortex, and hippocampus. We then measured tissue levels of expression and/or activity of MAO, catechol$O$-metyltransferase (COMT), dopamine- $\beta$-hydroxylase (DBH), tyrosine hydroxylase $(\mathrm{TH})$ and tryptophan hydroxylase (TRH) as well as estradiol levels in these regions. Our results show that amitraz did not
\end{abstract}

Abbreviations: AD, aldehyde dehydrogenase; AMZ, amitraz; ARO, aromatase; AAADC, aromatic amino acid decarboxylase; CNS, central nervous system; COMT, catechol- $O$-metyltransferase; $\mathrm{Ct}$, cycle threshold; $\mathrm{DA}$, dopamine; $\mathrm{DBH}$, dopamine- $\beta$ hydroxylase; DOPA, 3,4-dihydroxyphenylalanine; DOPAC, 3,4-hydroxyphenylacetic acid; DHT, dihydrotestosterone; E2, 17 $\beta$-estradiol; FC, prefrontal cortex; HC, hippocampus; HPLC, high performance liquid chromatography; HVA, homovanillic acid; 5-HT, serotonin; 5-HTP, 5-hydroxytryptophan; 5-HIAA, 5-hydroxy-3indolacetic acid; $\mathrm{LD}_{50}$, Lethal Dose 50; LOQ Quantification limit; MAO, monoamine oxidase; MHPG, 3-metoxy-4-hydroxyphenylethyleneglycol; NE, norepinephrine; NSD-1015, m-hydroxymethylhydrazine; SD, standard deviation; ST, striatum; T, testosterone; TH, tyrosine hydroxylase; TMX, tamoxifen; TRH, tryptophan hydroxylase.

* Corresponding author. Department of Toxicology and Pharmacology, Veterinary School, Universidad Complutense de Madrid, Avda. Puerta de Hierro s/n, 28040 Madrid, Spain.

E-mail address: jdelpino@pdi.ucm.es (J. del Pino).

1 These authors have contributed equally to this work. 
inhibit MAO activity at these doses, but altered MAO, COMT, DBH, TH and TRH gene expression, as well as TH and TRH activity and estradiol levels. The alteration of these enzymes was partially mediated by dysregulation of estradiol levels. Our present results provide new understanding of the mechanisms contributing to the harmful effects of amitraz.

๑) 2017 Elsevier Ltd. All rights reserved.

\section{Introduction}

Amitraz (1,5 di-(2,4-dimethylphenyl)-3-methyl-1,3,5-triazapenta-1,4-diene), a formamidine pesticide, is used worldwide on both animals and crops to control pests as an insecticide and acaricide (Yilmaz and Yildizdas, 2003). The pesticidal action of amitraz in invertebrates is related to activation of octopamine receptors (Nathanson, 1985). A cause of concern for health authorities is the number of amitraz human poisoning cases that have been attributed and are still being reported (Demirel et al., 2006; Veale et al., 2011).

Amitraz is a potent neurotoxic compound that induces signs such as loss of righting reflex, motor incoordination, appetite alteration, hyperreactivity to external stimuli, aggressiveness, among other effects. These effects are mediated in part by disruption of neurotransmitter systems (Del Pino et al., 2015). Amitraz (20, 50 and $80 \mathrm{mg} / \mathrm{kg} \mathrm{bw}$ ) increases serotonin (5-HT), norepinephrine (NE) and dopamine (DA) levels and decreases their metabolites levels and turnover rates in the central nervous system (CNS) of male rats with the striatum, prefrontal cortex, and hippocampus being the most affected (Del Pino et al., 2013). Although the mechanisms responsible for these alterations are not completely understood, amitraz inhibits monoamine oxidase (MAO), the main enzyme that metabolizes monoamine neurotransmitters (Aziz and Knowles, 1973). Therefore, amitraz could mediate the effects observed on monoaminergic neurotransmitters by blocking MAO. In this regard, Florio et al. (1993), showed that amitraz at dose of $100 \mathrm{mg} / \mathrm{kg}$ bw increased NE and DA levels in hypothalamus and striatum, respectively, and decreased the homovanillic acid (HVA) levels in striatum and attributed these effects to MAO inhibition. Moser and MacPhail (1989) reported that amitraz inhibits MAO only at doses of $100 \mathrm{mg} / \mathrm{kg}$ bw, so this mechanism could not explain the effect seen at lower doses. However, motor incoordination appears from doses lower than $100 \mathrm{mg} / \mathrm{kg}$ bw (from 6.25 to $25 \mathrm{mg} / \mathrm{kg}$ bw/day) in rats (Moser et al., 1987), and it has been reported that MAO inhibition mediates motor incoordination (Florio et al., 1993), suggesting this enzyme could mediate the monoamine neurotransmitters alteration observed at doses lower than $100 \mathrm{mg} / \mathrm{kg}$ bw.

Another explanation for amitraz-induced alterations in the NE, DA and 5-HT and its metabolites levels observed in male rats is that the pesticide may alter sex steroid hormones that regulate the activity and expression of enzymes important for neurotransmitter synthesis and metabolism. Such enzymes include aldehyde dehydrogenase (AD), catechol-O-metyltransferase (COMT), dopamine$\beta$-hydroxylase (DBH), MAO, tyrosine hydroxylase ( $\mathrm{TH})$, and tryptophan hydroxylase (TRH), all important for neurotransmitters synthesis and metabolism (Babu and Vijayan, 1984; Chaube and Joy, 2011; Donner and Handa, 2009; De Souza Silva et al., 2009; Handa et al., 1997; Lubbers et al., 2010; Luine and Rhodes, 1983; PurvesTyson et al., 2012; Rahman and Thomas, 2013; Scardapane and Cardinali, 1977; Schendzielorz et al., 2011; Thiblin et al., 1999). This hypothesis is reasonable considering that amitraz alters hepatic metabolism of $17 \beta$-estradiol (E2) and testosterone (T) in rats, and increases serum $\mathrm{T}$ in male rats at doses of 25 and $50 \mathrm{mg} /$ kg bw (Chou et al., 2008).

Aromatase (ARO) or reductase enzymes can metabolize T in CNS to E2 or dihydrotestosterone (DHT) in a region-specific manner (Castelli et al., 2013; Zhao et al., 2007, 2008). Therefore, the amitraz effect on monoaminergic neurotransmitter in male rats could be mediated by changes in T or its E2 or DHT metabolites. This idea is supported by evidence that $\mathrm{E} 2$ regulates the expression of enzymes which form and metabolize 5-HT, DA and NE (Donner and Handa, 2009; Luine and Rhodes, 1983; Luine et al., 1973; Scardapane and Cardinali, 1977; Serova et al., 2002). In this regard, E2 has been reported to induce TRH-2 mRNA expression (Donner and Handa, 2009) and to increase levels of mRNA encoding TH, the major rate limiting enzyme in DA and NE biosynthesis (Serova et al., 2002). In addition, synthesis and metabolism of monoaminergic neurotransmitters are modulated by $\mathrm{T}$ and DHT hormones (Thiblin et al., 1999). These hormones increase COMT, MAO-A and MAO-B mRNAs levels and TH protein enzymes (Purves-Tyson et al., 2012). Also, DHT reduces 5-HT, DA and NE turnover rates of gonadectomized animals (Handa et al., 1997). Taking all the above into consideration, we hypothesized that amitraz effects on serotoninergic, noradrenergic and dopaminergic systems may be mediated through a combination of MAO inhibition, and/or by altering sex steroid-dependent expression and activity of the enzymes that metabolize and synthesize these neurotransmitters.

This study sets out to analyze the presented hypothesis on the importance of monoaminergic neurotransmitter dysregulation for explaining amitraz neurotoxic effects. We evaluated this hypothesis by testing dose-dependent effects of amitrz (20, 50 and $80 \mathrm{mg} / \mathrm{kg}$ bw for 5 days) in striatum, prefrontal cortex, and hippocampus from male rats. Specifically, we tested whether amitraz inhibits MAO and/or alters the expression and activity enzymes that metabolize or synthesize the monoaminergic neurotransmitters and does so by altering sex hormones in these regions.

\section{Materials and methods}

\subsection{Chemicals}

Amitraz (98\%), dihydroxybenzoic acid, S-adenosyl-L-methionine, $m$-hydroxymethylhydrazine (NSD-1015) were obtained from Sigma (Madrid, Spain). All other chemicals were reagent grade of the highest laboratory purity available.

\subsection{Animals and experimental design}

European Union guidelines (2003/65/EC) and Spanish regulations (BOE 67/8509-12,1988) regarding the use of laboratory animals were followed when performing all experiments. We used male Wistar rats, at 60 days old, each weighting 200-210 g (Charles River, Barcelona, Spain), which were individually housed and maintained in a temperature- and light-controlled room (14:10 light:dark cycle; lights on at $0500 \mathrm{~h}$ ) with food and water available ad libitum. We randomly assigned 6 animals to each of the control and treatment groups. We used independent groups of controls and treatments for all different analyses performed. Animals were 
orally treated with either corn oil, as a vehicle, tamoxifen (TMX, $1 \mathrm{mg} / \mathrm{kg}$ bw subcutaneously), or amitraz at the dose of 20,50 and $80 \mathrm{mg} / \mathrm{kg}$ bw with or without TMX, all for 5 consecutive days. Food from treated group was removed $6 \mathrm{~h}$ before treatment, but animals were allowed water ad libitum. The doses of 20,50 and $80 \mathrm{mg} / \mathrm{kg}$ bw [equivalent to $1 / 30,1 / 12$ and $1 / 7.5$ of the $\mathrm{LD}_{50}$ (mean $\mathrm{LD}_{50}$ was previously calculated, data not shown)] were chosen because they were previously described to produce a dose-dependent alteration of monoamine neurotransmitters 5-HT, NE, DA and their metabolites after 5 consecutive days of treatment (Del Pino et al., 2013) and because they are under the doses that have been reported to inhibit MAO (Moser and MacPhail, 1989), which was the mechanism suggested to produce this alteration (Florio et al., 1993). Thus, the selected doses are relevant to study the mechanisms of alteration of these monoaminergic neurotransmitters. TMX, a selective estrogen receptor antagonist, was used at $1 \mathrm{mg} / \mathrm{kg}$ bw dose as an effective dose according to literature (Okamoto et al., 2012; Nayebi et al., 2014) and the minimum dose that induced the maximum blockage on amitraz effects (data not shown).

Three hours after the last dose of treatment, animals were euthanized by decapitation. Brains were rapidly removed, and hippocampus, prefrontal cortex and striatum were dissected out at $4{ }^{\circ} \mathrm{C}$ (Glowinski and Iversen, 1966) under a stereomicroscope (Olympus SZ51, Barcelona, Spain). Tissues samples were quickly weighed and stored at $-80^{\circ} \mathrm{C}$ until further analysis.

\subsection{Estradiol and testosterone quantification}

$\mathrm{E}_{2}$ and $\mathrm{T}$ content was measured in plasma, hippocampus, prefrontal cortex and striatum from treated animals in order to determine whether sex hormones are altered by amitraz exposure. $\mathrm{E}_{2}$ and $\mathrm{T}$ content was measured using an enzyme immunoassay kit (Estradiol EIA Kit, Cayman Chemical Company, MI, USA), according to the manufacturer's instructions. Plasma samples were extracted twice with ethyl acetate and tissues samples were homogenized in $300-500 \mu \mathrm{L}$ of an equal mixture of ethyl acetate and $0.1 \mathrm{M}$ phosphate-buffered saline. Homogenates were centrifuged at $21,000 \times \mathrm{g}$ for $15 \mathrm{~min}$ at $4{ }^{\circ} \mathrm{C}$. The mixture was afterwards incubated in a $\mathrm{MeOH} / \mathrm{dry}$ ice bath to solidify the aqueous phase, while the organic phase was eluted into a new tube. After, ethyl acetate portion was gathered and dried. The dried material was reconstituted in $120 \mu \mathrm{L}$ EIA buffer, and $100 \mu \mathrm{L}$ of the sample was used for EIA at duplicate. ELISA values were obtained $(\mathrm{ng} / \mathrm{mL})$ and corrected for plasma volume $(\mathrm{mL} / \mathrm{mL})$ or weight tissue $(\mathrm{mg} / \mathrm{mL})$, producing a final unit of $\mathrm{pg} / \mathrm{mL}$ or $\mathrm{pg} / \mathrm{mg}$, respectively, and presented as a percentage of the untreated control.

\subsection{Aromatase activity analysis}

Brain ARO activity was determined using the tritiated water $\left(3 \mathrm{H}_{2} \mathrm{O}\right)$ release method, based on the production of $3 \mathrm{H}_{2} \mathrm{O}$ during aromatization of a labeled androgenic substrate. The formation of tritiated water is proportional to the amount of estrogen produced during aromatization. Brain tissues were homogenized and afterwards subjected to the $3 \mathrm{H}_{2} \mathrm{O}$ release assay as previously described (Grote et al., 2006; Hobler et al., 2010). Briefly, dissected brain samples were homogenized in TEKS buffer (Tris $\mathrm{HCl} 50 \mathrm{mM}, \mathrm{Na}_{2}$ EDTA $2 \mathrm{H} 201 \mathrm{mM}, \mathrm{KCl} 100 \mathrm{mM}$ pH 7.4) containing 0.1\% (w/v) $\mathrm{Na}_{2} \mathrm{~S}_{2} \mathrm{O}_{5}$. The homogenized samples $(20 \mu \mathrm{L})$ were incubated, at $37{ }^{\circ} \mathrm{C}$ for $30 \mathrm{~min}$, with $20 \mu \mathrm{L}$ TEKS buffer and $10 \mu \mathrm{L}$ NADPH ( $5 \mathrm{mg} /$ $\mathrm{ml}$ ) in 96-well plates, containing the tracer $[1 \beta-3 \mathrm{H}(\mathrm{N})]$-androst-4ene-3,17-dione (Perkin Elmer, Madrid, Spain) previously added. Protein concentration was determined in one aliquot of the homogenate using a BCA kit (Thermo Fisher Scientific, Madrid, Spain). The reaction was finished in an ethanol-dry-ice bath and cold water was added up to a volume of $150 \mu \mathrm{L}$ per well. The content of the wells was afterwards transferred onto clean-up C-18 extraction columns (UCT, Bristol, England), preconditioned with methanol and ethanol, and subsequently centrifuged for $5 \mathrm{~min}$ at $2000 \mathrm{rpm}$ and $4{ }^{\circ} \mathrm{C}$. The columns were centrifuged again after adding $200 \mu \mathrm{L}$ distilled water under the same conditions. Radioactivity corresponding to the reaction product was measured by organic liquid scintillation counting. ARO activity was expressed as $\mathrm{fmol} / \mathrm{mg}$ protein/15 min and values were expressed as the percentage of enzyme activity.

\subsection{Determination of monoamine levels}

Monoamine levels were determined in hippocampus, prefrontal cortex and striatum after amitraz treatment with or without TMX to study the effect on monoaminergic transmission. The tissues were homogenized in $300-500 \mu \mathrm{L}$ of $0.4 \mathrm{M} \mathrm{HClO}_{4}$ containing $0.1 \%(\mathrm{w} / \mathrm{v}) \mathrm{Na}_{2} \mathrm{~S}_{2} \mathrm{O}_{5}$ by sonication. Homogenates were centrifuged, at $4{ }^{\circ} \mathrm{C}$, for $15 \mathrm{~min}$ at $20.000 \times \mathrm{g}$ and aliquots of supernatants were taken for analysis of 5-HT and its metabolite [5-hydroxy-3indolacetic acid (5-HIAA)], DA and its metabolites [3,4hydroxyphenylacetic acid (DOPAC) and HVA] and NE and its metabolite [3-metoxy-4-hydroxyphenylethyleneglycol (MHPG)] using a high performance liquid chromatography (HPLC) technique as described previously (Del Pino et al., 2013).

The sample chromatograms' peak areas were quantified as described previously by Del Pino et al. (2013). Quantification limit (LOQ) was $2 \mathrm{pg}$ for DA, DOPAC, NE, 5-HT and 5-HIAA and $20 \mathrm{pg}$ for HVA and MPHG in the different tissue matrices. 5-HT, DA and NE turnover rates were calculated as ratios of metabolites to neurotransmitter. Concentrations were expressed as ng per g of wet tissue and values were expressed as the percentage of control.

\subsection{TH and TRH activity analysis}

The activities of TH and TRH in the brain regions studied were indirectly calculated as previously stated (Johnston and Moore, 1983; Nissbrandt et al., 1988), by measuring 3,4-dihydroxyphenylalanine (DOPA) and 5-hydroxytryptophan (5-HTP) accumulation, respectively, after aromatic amino acid decarboxylase (AAADC) inhibition, with $m$-hydroxymethylhydrazine (NSD-1015). 30 min before animals sacrifice, all groups of animals used for this particular experiment were injected intraperitoneally with NSD1015 (100 mg/kg bw). At this dose, NSD-1015 is able to completely blockage AAADC activity, leading to DOPA and 5-HTP accumulation. Homogenates prepared as described above were centrifuged, at $4{ }^{\circ} \mathrm{C}$, for $15 \mathrm{~min}$ at $20.000 \times \mathrm{g}$ and aliquots of supernatants were taken for analysis of DOPA and 5-HTP levels using a HPLC technique as described previously by Chapin et al. (1986). 5HTP and L-DOPA concentrations were expressed as ng per mg of protein per $30 \mathrm{~min}$ and values were expressed as the percentage of enzyme activity.

\subsection{Catechol-O-methyltransferase activity and protein content analysis}

COMT activity was measured in prefrontal cortex, hippocampus and striatum as described earlier (Nissinen and Männistö, 1984; Reenilä et al., 1995). Briefly, $100 \mu \mathrm{L}$ enzyme preparation was incubated at $37{ }^{\circ} \mathrm{C}$ for $30 \mathrm{~min}$ in the presence of $5 \mathrm{mM} \mathrm{MgCl}_{2}, 240 \mu \mathrm{M}$ dihydroxybenzoic acid, and $200 \mu \mathrm{M}$ S-adenosyl-L-methionine in $100 \mathrm{mM}$ sodium phosphate buffer, $\mathrm{pH}$ 7.4. The reaction was stopped with ice-cold $0.4 \mathrm{M}$ perchloric acid and centrifuged, at $4{ }^{\circ} \mathrm{C}$, at $5530 \times \mathrm{g}$ for $10 \mathrm{~min}$. A HPLC system with electrochemical detection was used to analyze the reaction products, vanillic and isovanillic 
acid and protein content was measured by BCA kit (Thermo Fisher Scientific, Madrid, Spain). COMT activity is expressed as picomoles vanillic acid formed in one min per mg of protein in the sample and values were expressed as the percentage of enzyme activity.

Commercial ELISA kit (MBS2880296, MyBiosource, CA, USA) was used to assay COMT protein concentration according to the manufacturer's instructions. Concentrations were calculated as $\mathrm{ng} / \mathrm{mg}$ of protein and values were expressed as the percentage of enzyme control content.

\subsection{Dopamine- $\beta$-hydroxylase activity analysis}

DBH activity was determined by using the two-wavelength spectrophotometric method of Kato et al. (1974). The DBH assay is based on the enzymatic conversion of tyramine to octopamine. The product octopamine was isolated by using small column that contained $0.2 \mathrm{~mL}$ of activated DOWEX-50WX4 $\left(\mathrm{H}^{+}, 200-400\right.$ mesh) resin. The adsorbed octopamine was eluted with $1.0 \mathrm{~mL}$ of $3 \mathrm{~N} \mathrm{NH}_{4} \mathrm{OH}$, and then converted into $p$-hydroxybenzaldehyde by addition of $10 \mu \mathrm{L}$ of $2 \% \mathrm{NaIO}_{4}$ solution. The $\mathrm{NaIO}_{4}$ excess was reduced by adding $10 \mu \mathrm{L}$ of $10 \% \mathrm{Na}_{2} \mathrm{~S}_{2} \mathrm{O}_{3}$ solution. The solution was extracted with $5 \mathrm{~mL}$ ethyl ether, the ether phase was again extracted with $1 \mathrm{~mL}$ of $3 \mathrm{~N} \mathrm{NH}_{4} \mathrm{OH}$ for absorbance measurements at $330 \mathrm{~nm}$. DBH activity was expressed as nmol (octopamine)/min/g of wet tissue and values were expressed as the percentage of enzyme activity.

\subsection{Real-time PCR analysis}

The ARO expression, in control and amitraz treated animals, was measured in hippocampus, prefrontal cortex and striatum tissues, in order to determine whether its alteration by amitraz is a possible mechanism of $\mathrm{E}_{2}$ disruption. Moreover, monoamine oxidase $\mathrm{A}$ (MAOA), monoamine oxidase B, (MAOB), COMT, TH, TRH and DBH expression was measured in hippocampus, prefrontal cortex and striatum tissues from control and amitraz treated animals with or without TMX in order to determine whether amitraz, through $\mathrm{E}_{2}$ disruption, alters the expression of these enzymes. Total RNA was extracted using the Trizol Reagent method (Invitrogen, Madrid, Spain). The final RNA concentration was determined using a Nanodrop 2000 spectrophotometer (Thermo Fisher Scientific, Madrid, Spain), and the quality of total RNA samples was assessed using an Experion LabChip (Bio-Rad, Madrid, Spain) gel. Firststrand cDNA was synthesized with 1000 ng of cRNA by using a PCR array first strand-synthesis kit (C-02; SuperArray Bioscience, Madrid, Spain) in accordance with the manufacturer's instructions and including a genomic DNA elimination step and external RNA controls. After reverse transcription, semi quantitative real-time PCR was carried out using prevalidated primer sets (SuperArray Bioscience) for mRNAs encoding ARO (PPR47164A), MAOA (PPR46359A), MAOB (PPM03990A), COMT (PPR06789A), TH (PPR45220F), TRH (PPR48244A), DBH (PPR52652A), and ACTB (PPM02945B). ACTB was used as an internal control for normalization. Reactions were run on a CFX96 using Real-Time SYBR Green PCR master mix PA-012 (SuperArray Bioscience). The thermocycler parameters were $95^{\circ} \mathrm{C}$ for $10 \mathrm{~min}$, followed by 40 cycles of $95^{\circ} \mathrm{C}$ for $15 \mathrm{~s}$ and $72{ }^{\circ} \mathrm{C}$ for $30 \mathrm{~s}$. Relative changes in gene expression were calculated using the cycle threshold $(\mathrm{Ct})$ method. The expression data are presented as actual change multiples (Livak and Schmittgen, 2001).

\subsection{Monoamine oxidase activity and content measurement}

MAO activity was determined in hippocampus, prefrontal cortex and striatum homogenates by a luminescent method that uses a derivative of beetle luciferin as a luminogenic MAO substrate. Tissues were homogenized in cold phosphate buffer $0.1 \mathrm{M}(\mathrm{pH} 8.0$; $4 \mu \mathrm{L} / \mathrm{mg}$ tissue) supplemented with protease inhibitors and protein content was measured by BCA kit (Thermo Fisher Scientific, Madrid, Spain). Forty-five $\mu \mathrm{g}$ of protein in triplicate per rat tissue were used in the MAO-Glo Assay (Promega, Madrid, Spain) as described by the manufacturer, increasing the incubation with substrate from 20 min to 3 h. Luminescent signal was detected using a Fluoroskan Ascent FL plate reader (Thermo Fisher Scientific, Madrid, Spain). MAO activity, measured in relative light units (RLU), was background corrected using a buffer-only control and values were expressed as the percentage of enzyme activity. Heat-inactivated samples yielded similar background values to buffer-only controls. Since this assay could detect amine oxidases other than MAO, to confirm that the signal from rat tissues homogenates was due to MAO and not other amine oxidases, tissue homogenates were assayed in the presence of the specific MAO A and B inhibitors clorgyline and deprenyl, respectively, which completely inhibited the luminescent signal.

Commercial ELISA kits (MBS9328595 and MBS2881432, MyBiosource, CA, USA) were used to assay MAOA and MAOB, respectively, protein concentrations according to the manufacturer's instructions. Concentrations were calculated as $\mathrm{ng} / \mathrm{mg}$ of protein and values were expressed as the percentage of enzyme control content.

\subsection{Statistical analysis}

Results are expressed as mean \pm standard deviation (SD) of 6 animals per group and presented as percentage change from control (\%). Comparisons between experimental and control groups' raw data were carried out with either one-way ANOVA analysis (analysis of different treatments) or two-way ANOVA analysis (brain region vs treatment), followed by the Duncan post-hoc test. Statistical difference was accepted when $\mathrm{p} \leq 0.05$. Statistical analysis of data was carried out by computer using GraphPad software.

\section{Results}

Male rats treated with amitraz at the highest dose $(80 \mathrm{mg} / \mathrm{kg} \mathrm{bw}$, 5 days) showed a slight motor incoordination, approximately $1-2 \mathrm{~h}$ after treatment. These signs were reversible and approximately at $6 \mathrm{~h}$ after treatment the rats behaved normally. Male rats treated with amitraz (20, 50 and $80 \mathrm{mg} / \mathrm{kg}$ bw, 5 days) showed no statistically significant effect on the gain or loss of body weight, weight of tissues (brain regions), or the ratio weight tissue/body weight (\%) compared to control (data not shown).

\subsection{Estradiol and testosterone quantification}

$\mathrm{E}_{2}$ and $\mathrm{T}$ content was assessed in plasma, striatum, prefrontal cortex and hippocampus after 5 days treatment with vehicle or amitraz at doses of 20,50 and $80 \mathrm{mg} / \mathrm{kg}$ bw. Amitraz treatment showed no effect in the content of $E_{2}$ in plasma and $T$ in the brain regions studied (data not shown). However, amitraz induced a dose-dependent increase in $T$ content in plasma and $E_{2}$ content in the regions of prefrontal cortex, striatum and hippocampus from highest to lowest in this order (Fig. 1A and B).

\subsection{Aromatase activity analysis}

ARO activity was assessed in striatum, prefrontal cortex and hippocampus after 5 days treatment with amitraz at dose of 20, 50 and $80 \mathrm{mg} / \mathrm{kg}$ bw with or without TMX at dose of $1 \mathrm{mg} / \mathrm{kg}$ bw. Amitraz induced a dose-dependent increase in the activity of ARO 
A

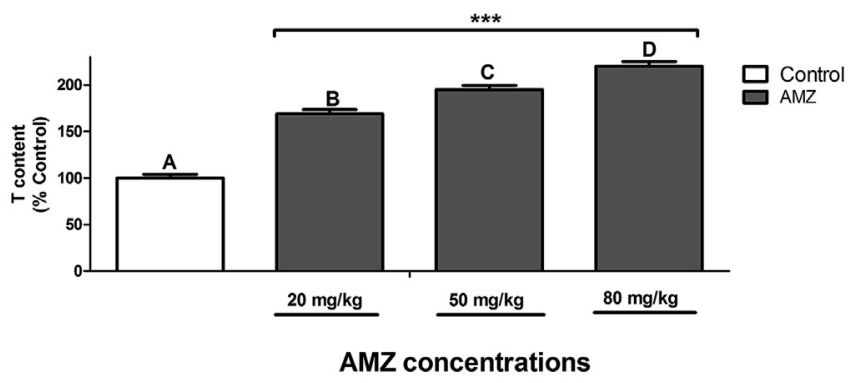

C

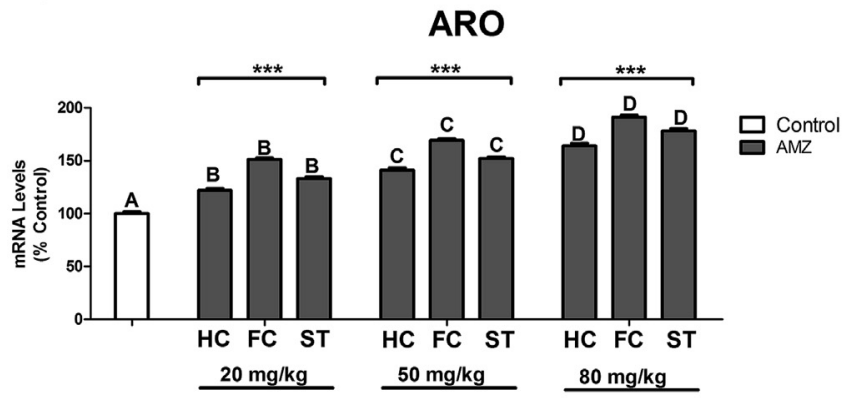

AMZ concentrations
B

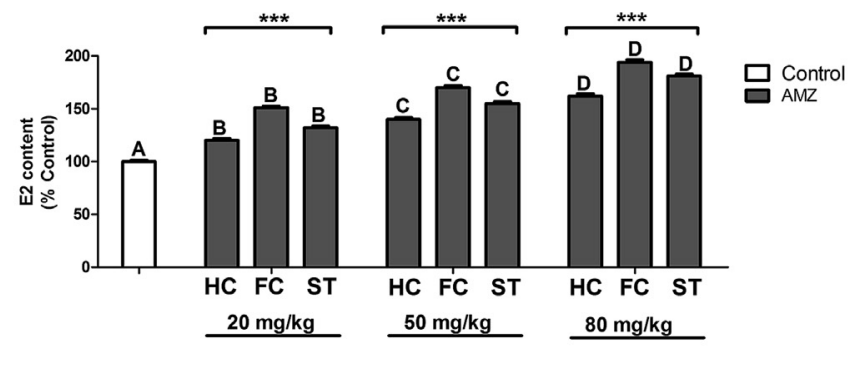

AMZ concentrations

D

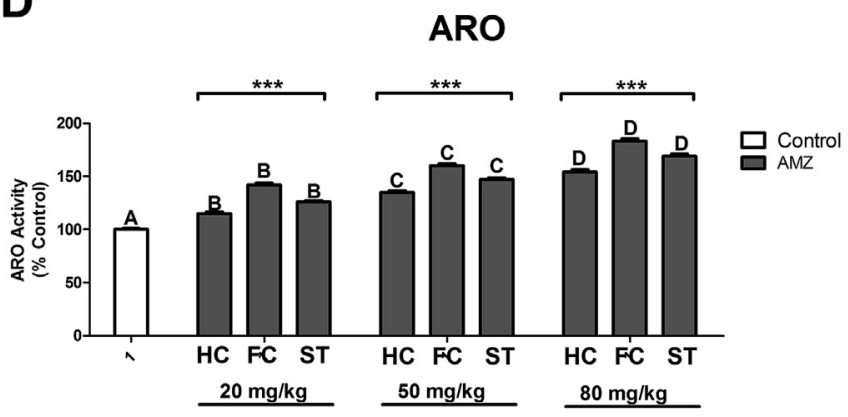

AMZ concentrations

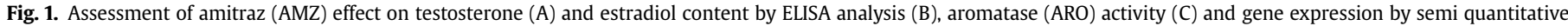

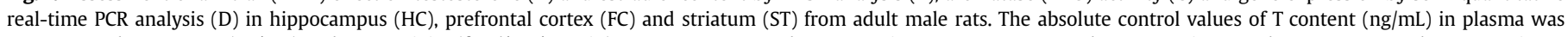

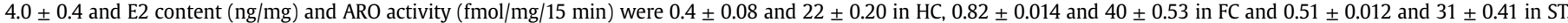

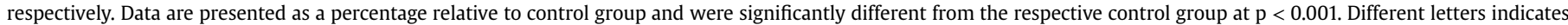
significant difference among different doses for each structure (Duncan's test). ${ }^{* * *}$ Significant difference between brain regions for each amitraz dose ( $\mathrm{p}<0.001$ ).

in prefrontal cortex, striatum, and hippocampus from highest to lowest in this order (Fig. 1C).

\subsection{Determination of monoamine levels}

Amitraz produced a dose-dependent increase of the 5-HT, DA and NE levels in all brain regions studied compared to the control group. Only the most affected brain region for each neurotransmitter is represented in Fig. 2 since data from the rest brain regions were similar, and the rest brain region of each neurotransmitter are represented in Supplementary Figures online. The increase of 5-HT ranged from highest to lowest in prefrontal cortex, striatum and hippocampus (Fig. 2A and Supplementary Fig. 1A and B). The increase of NE ranged from highest to lowest in striatum, hippocampus and prefrontal cortex (Fig. 2B and Supplementary Fig. 2A and $B$ ). The increase in DA ranged from highest to lowest in prefrontal cortex, striatum, and hippocampus (Fig. 2C and Supplementary Fig. 3A and B).

Moreover, amitraz induced a dose-dependent decrease of 5HIAA metabolite content and its turnover rate (5-HIAA/5-HT), MHPG metabolite content and its turnover rate (MHPG/NE) and DOPAC and HVA metabolites content and turnover rate (DOPAC + HVA/DA) in all brain regions studied compared to the control group. 5-HIAA and turnover rate decrease ranged from highest to lowest in prefrontal cortex, hippocampus and striatum (Fig. 2A and Supplementary Fig. 1A and B). MHPG decrease ranged from highest to lowest in prefrontal cortex, striatum and hippocampus and turnover rate decrease ranged from highest to lowest in striatum, prefrontal cortex and hippocampus (Fig. 2B and Supplementary Fig. 2A and B). There were no differences between the decrease in the DOPAC and HVA content in the hippocampus, but the decrease in the DOPAC content was higher than the decrease in the HVA content in the striatum, and the decrease in the HVA content was higher than the decrease in the DOPAC content in prefrontal cortex (Fig. 2C and Supplementary Fig. 3A and B). The decrease of DA turnover rate (DOPAC + HVA/DA) ranged from highest to lowest in prefrontal cortex, hippocampus and striatum (Fig. 2C and Supplementary Fig. 3A and B).

Treatment with TMX alone induced a dose-dependent decrease of the 5-HT, DA and NE levels, and a dose-dependent increase in their metabolites and their turnover rates in all brain regions studied compared to the control group (Fig. 3A-C). TMX cotreatment with amitraz partially reversed the change in 5-HT, NE and DA neurotransmitters and their metabolites levels as well as the turnover rates induced by amitraz alone in all brain regions studied (Fig. 2 and Supplementary Figs. 1-3).

\subsection{TH and TRH activity analysis}

After treatment, amitraz induced a dose-dependent increase in the activity of TH and TRH in prefrontal cortex, striatum, and hippocampus from highest to lowest in this order (Fig. 4A and B, respectively). TMX alone treatment induced a dose-dependent decrease in the activity of $\mathrm{TH}$ and $\mathrm{TRH}$ in the brain regions 
FRONTAL CORTEX
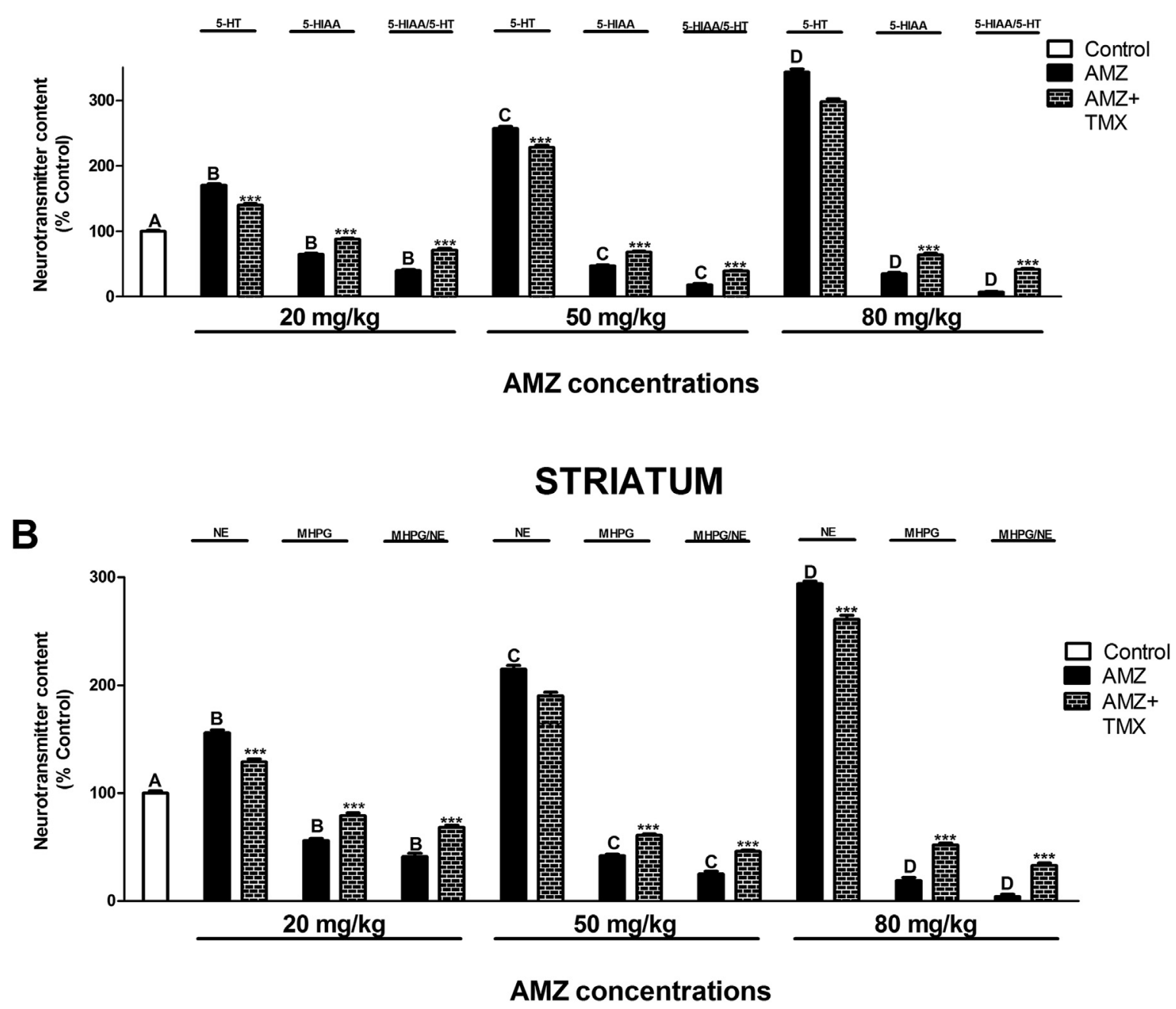

FRONTAL CORTEX

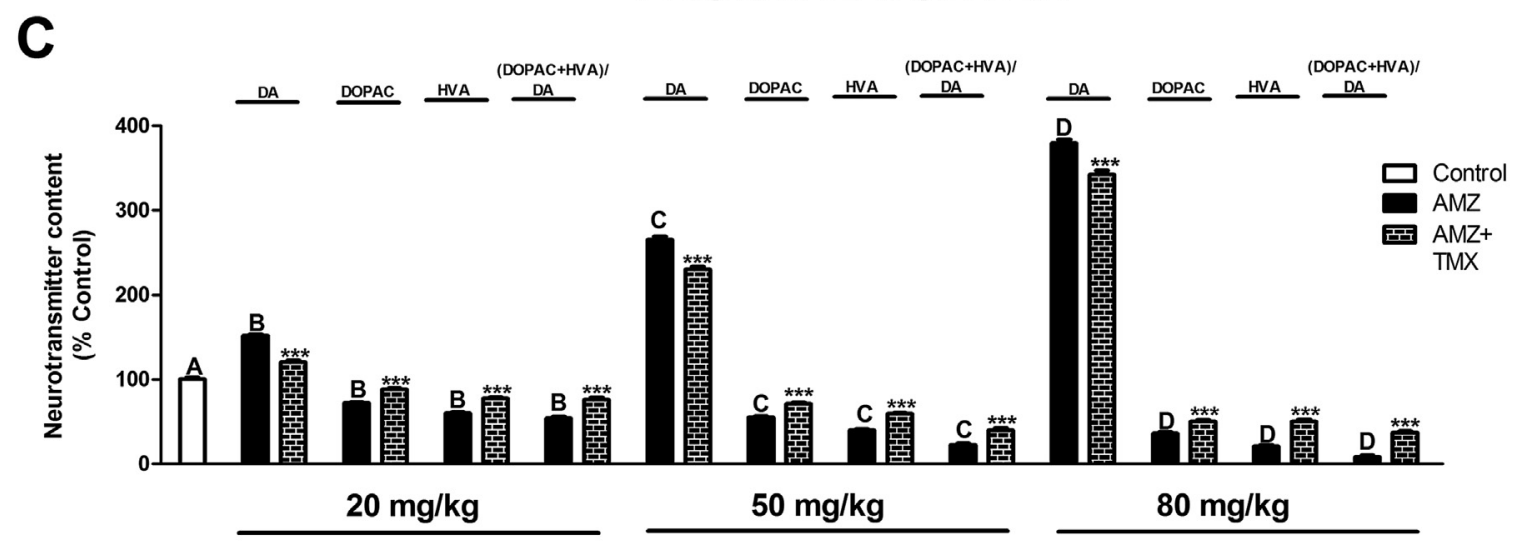

AMZ concentrations

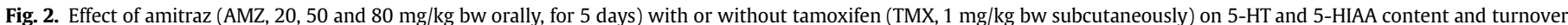

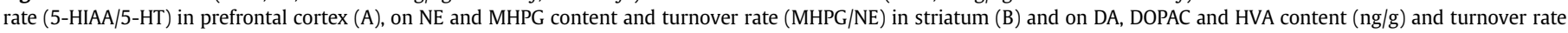




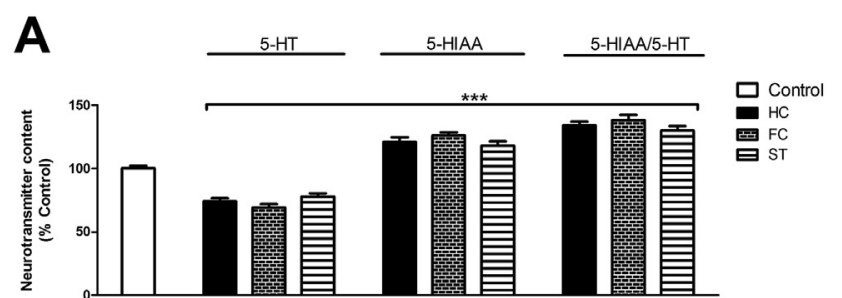

TMX concentration, $1 \mathrm{mg} / \mathrm{kg}$

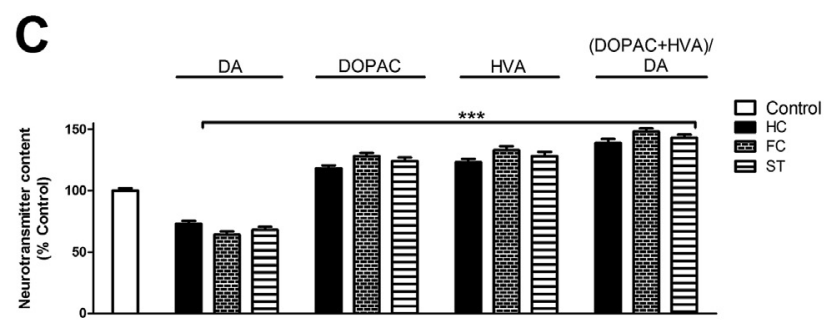

TMX concentration, $1 \mathrm{mg} / \mathrm{kg}$

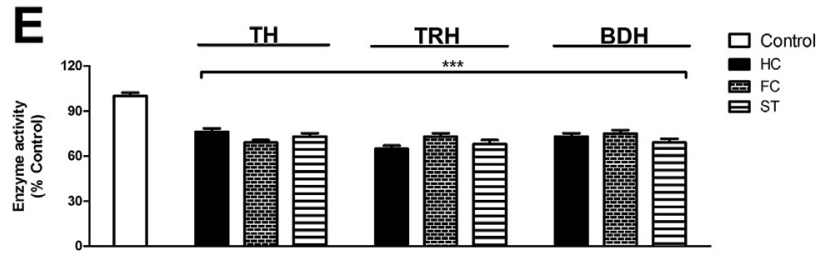

TMX concentration, $1 \mathrm{mg} / \mathrm{kg}$

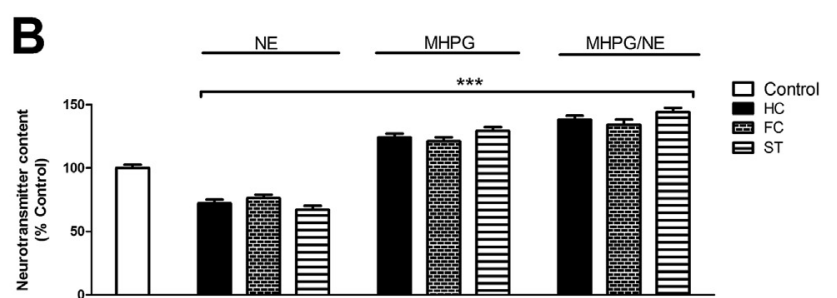

TMX concentration, $1 \mathrm{mg} / \mathrm{kg}$

D

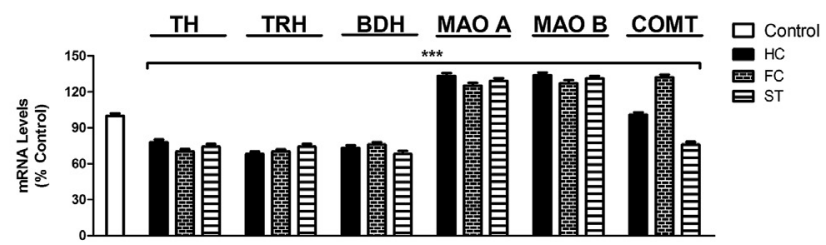

TMX concentration, $1 \mathrm{mg} / \mathrm{kg}$

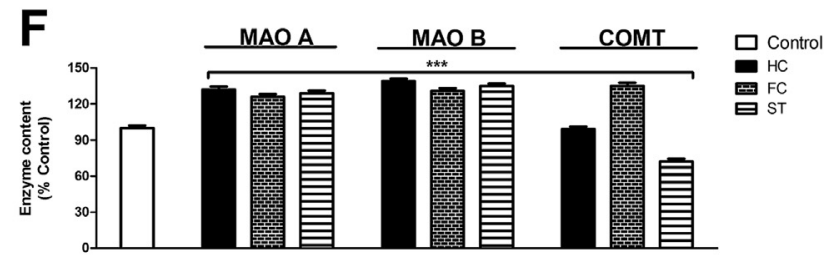

TMX concentration, $1 \mathrm{mg} / \mathrm{kg}$

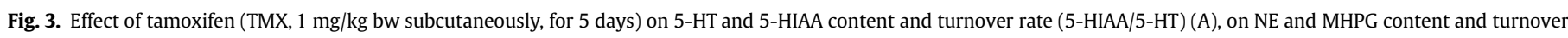

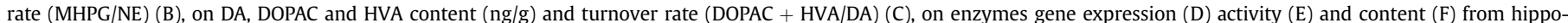

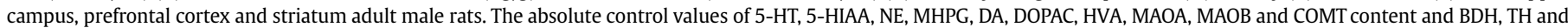

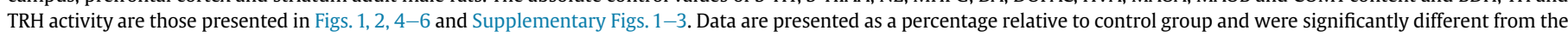
respective control group at $\mathrm{p}<0.001$. ${ }^{* *}$ Significant difference $(\mathrm{p}<0.001)$ compared to each amitraz dose.

studied (Fig. 3E). TMX co-treatment with amitraz partially reversed the effect observed on TH and TRH activity after amitraz alone treatment (Fig. 4A and B, respectively).

\subsection{Catechol-O-methyltransferase activity and protein content analysis}

Amitraz and TMX alone treatment showed no effect on COMT activity in the brain regions at the doses studied (data not shown). However, amitraz induced a dose-dependent decrease in COMT content in prefrontal cortex and an increase in striatum, but did not produced effect on COMT content in hippocampus (Fig. 5A). TMX alone treatment induced a dose-dependent increase in COMT content in prefrontal cortex and a decrease in striatum, but did not produced effect on COMT content in hippocampus (Fig. 3F). TMX co-treatment with amitraz partially reversed the effect observed on COMT content after amitraz alone treatment (Fig. 5A).

\subsection{Dopamine- $\beta$-hydroxylase activity analysis}

After treatment with amitraz or TMX alone a dose-dependent increase and decrease in the activity of DBH in striatum, hippocampus and prefrontal cortex, from highest to lowest in this order was observed, respectively (Figs. 5B and 3E, respectively). TMX cotreatment with amitraz partially reversed the effect observed on DBH activity after amitraz alone treatment (Fig. 5B).

\subsection{Real-time PCR analysis}

Amitraz treatment at dose of 20,50 and $80 \mathrm{mg} / \mathrm{kg}$ bw for 5 days induced an increase in the expression of ARO in prefrontal cortex, striatum, and hippocampus from highest to lowest in this order (Fig. 1D). Moreover, amitraz induced an increase in the expression of TH and TRH in prefrontal cortex, striatum, and hippocampus from highest to lowest in this order (Fig. 4C and D). In addition,

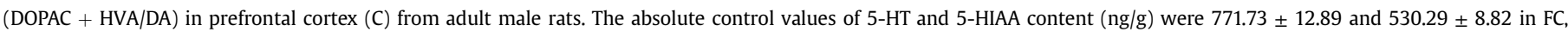

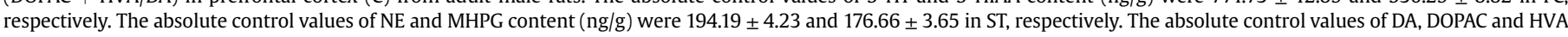

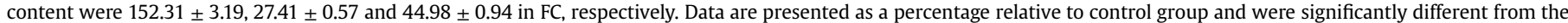

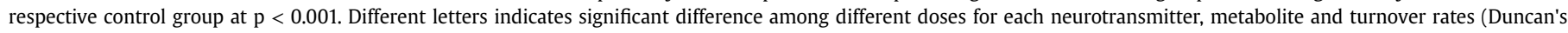
test). ${ }^{* * *}$ Significant difference $(\mathrm{p}<0.001)$ compared to each amitraz dose. 
A

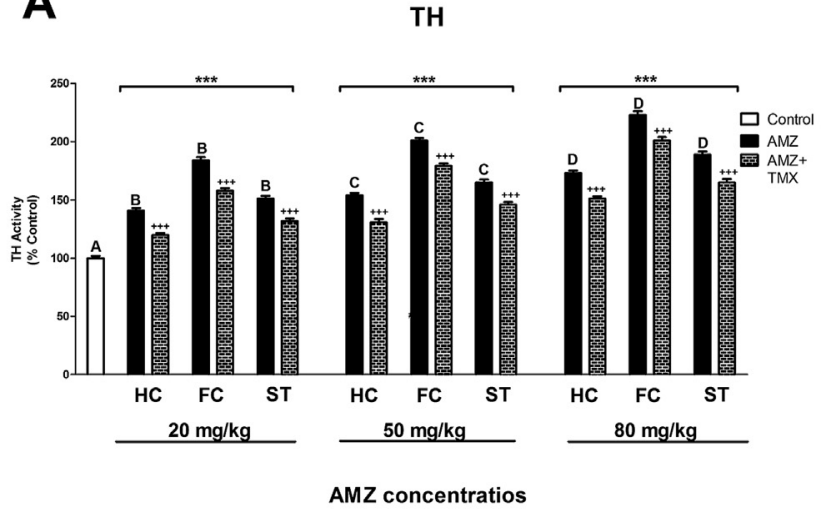

C

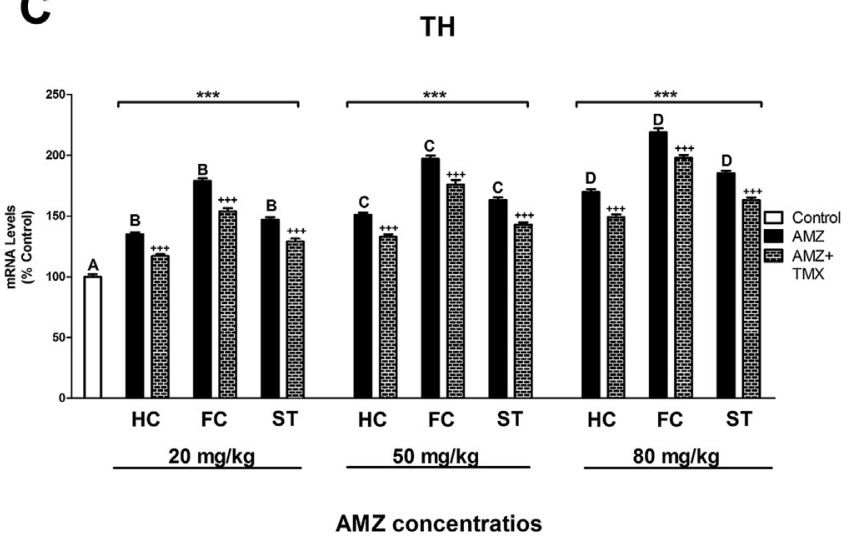

B
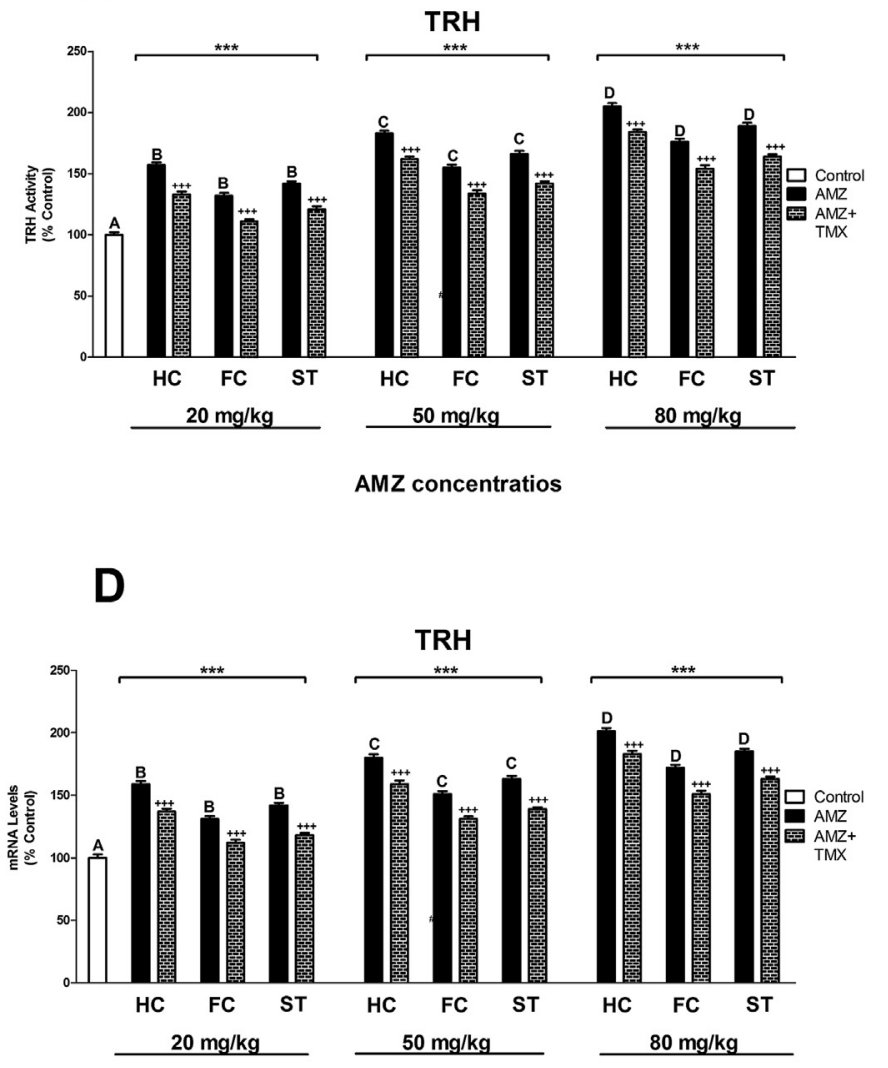

AMZ concentratios

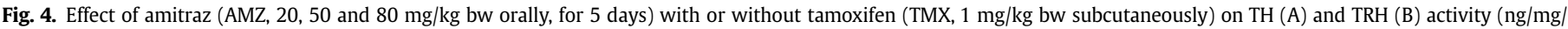

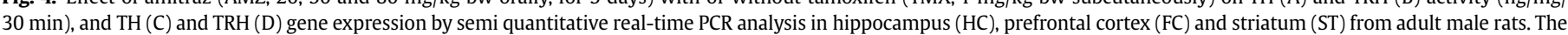

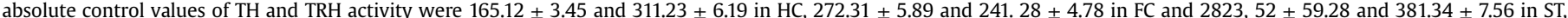

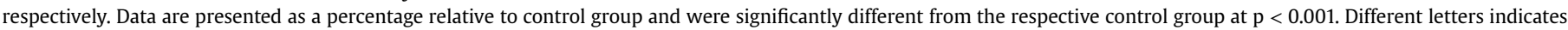

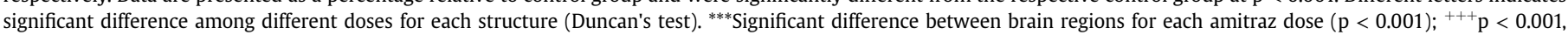
significantly different compared to each amitraz dose.

amitraz treatment did not produced effect on COMT expression in hippocampus, but induced a decrease in its expression in prefrontal cortex and an increase in its expression in striatum (Fig. 5C). Also, amitraz increased DBH expression in striatum, hippocampus and prefrontal cortex, from highest to lowest in this order (Fig. 5D). Finally, amitraz decreased MAO A and MAO B expression in prefrontal cortex, striatum, and hippocampus from highest to lowest in this order (Fig. 6A and B). TMX alone treatment induced an opposite effect on the expression of these enzymes than that observed after amitraz alone treatment (Fig. 3D) and its co-treatment with amitraz partially reversed the effects induced after amitraz alone treatment (Figs. 1D, 4C, D, 5C, D, 6A and B).

\subsection{Monoamine oxidase activity and content measurement}

MAO activity measurements in prefrontal cortex, striatum and hippocampus after 5 days vehicle or amitraz at the dose of 20,50 and $80 \mathrm{mg} / \mathrm{kg}$ bw and TMX treatment showed no effect in the brain regions studied (Data not shown). In addition, amitraz and TMX induced a decrease and an increase in MAO A and MAO B content in prefrontal cortex, striatum, and hippocampus from highest to lowest in this order, respectively (Fig. 6C and D and Fig. 3F, respectively). TMX co-treatment with amitraz partially reversed the effect observed on MAO A and B content after amitraz alone treatment (Fig. 6C and D).

\section{Discussion}

In the present work, we showed that amitraz increases serum $\mathrm{T}$ levels in a dose-dependent way as reported previously in male rats (Chou et al., 2008). We also found that amitraz increases $E_{2}$ serum levels and ARO enzyme expression and activity in prefrontal cortex, striatum and hippocampus ranging from highest to lowest in this order. It seems likely that the increase in serum $T$ levels increases brain levels of $\mathrm{T}$ and amitraz-induced upregulation of ARO that would be expected to convert T to $\mathrm{E}_{2}$. Moreover, endogenous synthesis of $E_{2}$ in the brain, independent of gonadal synthesis, has been reported to take place (Ikeda et al., 2015). Therefore, we cannot rule out that there might be an endogenous synthesis of neural $E_{2}$ induced by amitraz, independently from circulating $\mathrm{T}$ levels that could control or contribute to the observed effects.

At the doses we used, amitraz did not alter the activity of MAO, indicating that MOA dysregulation does not explain the observed effects on monoamine neurotransmitters at doses lower than $100 \mathrm{mg} / \mathrm{kg}$ bw as suggested previously by Moser and MacPhail (1989). However, at doses lower than $100 \mathrm{mg} / \mathrm{kg}$ bw, amitraz downregulated, in a dose-dependent way, MAO expression and content following an order from highest to lowest decrease in prefrontal cortex, striatum and hippocampus. Thus, inhibition of MAO synthesis mays explain, in part, the effects observed on 
A

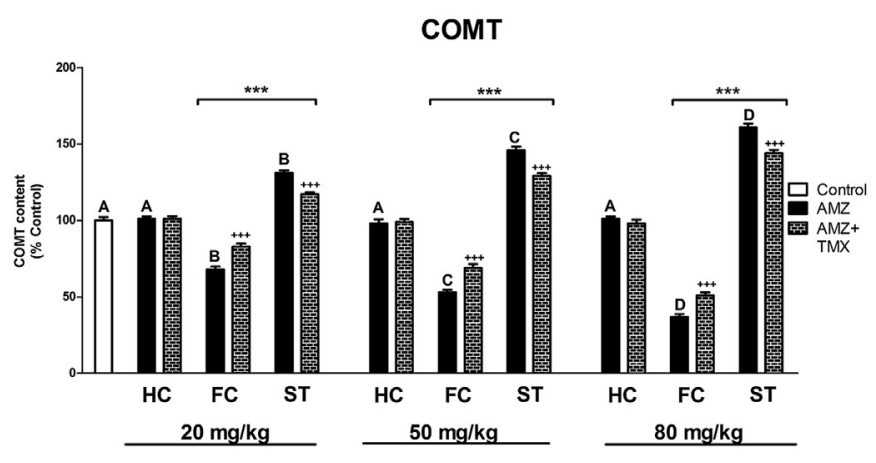

AMZ concentrations

C

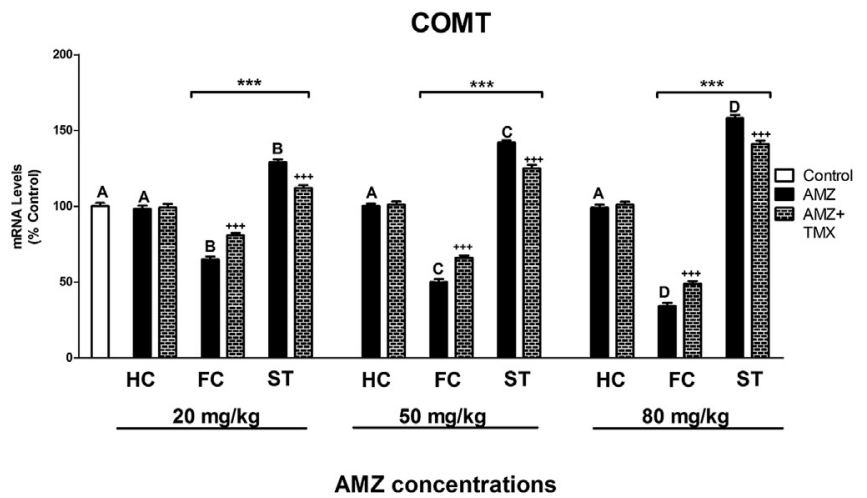

B

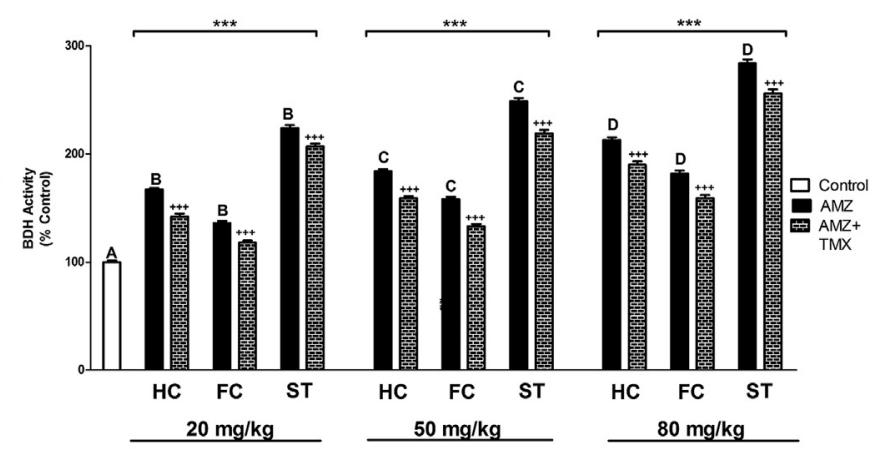

AMZ concentratios

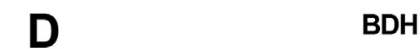

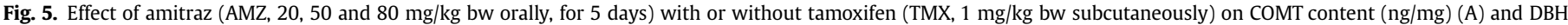

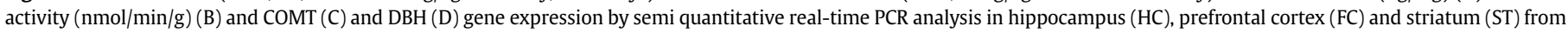

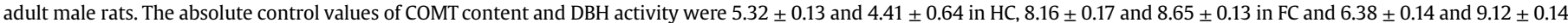

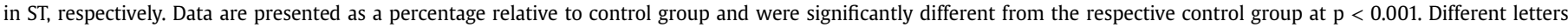

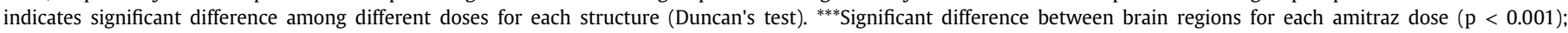
${ }^{++} \mathrm{p}<0.001$, significantly different compared to each amitraz dose.

monoaminergic neurotransmitters at doses lower than $100 \mathrm{mg} / \mathrm{kg}$ bw.

Our finding that amitraz altered, in a dose- and regiondependent way, the activity and expression of TH, TRH and DBH and of COMT expression and content, could also explain, in part, the effects observed effects on monoaminergic neurotransmitters in the brain regions studied. In this regard, the induction of THR and $\mathrm{TH}$ in prefrontal cortex, striatum and hippocampus is correlated with the increase in the content of 5-HT and DA. In fact, the regions with the highest levels of THR and TH also had the greatest increase in 5-HT and DA. However, the increase of TH activity and expression was not correlated with the increase of NE in striatum, hippocampus and prefrontal cortex; instead they were correlated with the increases in the activity and expression of $\mathrm{DBH}$, the enzyme that synthesize NE from DA. Thus, the effect of amitraz on NE synthesis is likely mediated by DBH, not TH and could explain the differences observed between DA and NE neurotransmitters in these regions. Similarly, the decrease of MAO content in these regions was correlated with the decrease in the metabolites of 5-HT, DA and NE and changes in COMT content in striatum and prefrontal cortex could explain the observed effects on DOPAC and HVA content in these regions. The alteration in all the studied enzymes and neurotransmitters was partially reversed in all cases by co-treatment with amoxifen, an estrogen receptor antagonist. This suggests that amitraz alters a number of neurotransmitter systems, at least in part, by disrupting $\mathrm{E}_{2}$ regulation of the enzymes that synthesize and metabolize these neurotransmitters.

Sex hormones alter monoaminergic and indolaminergic neurotransmitter systems in the CNS through effects on synthesis, vesicular and/or synaptic release and metabolism regulation (Meyers et al., 2010). Particularly, activity and expression of enzymes that synthesize and metabolize DA, NE and 5-HT are altered by E2 (Babu and Vijayan, 1984; Chaube and Joy, 2011; Donner and Handa, 2009; Luine and Rhodes, 1983; Luine et al., 1973; Rahman and Thomas, 2013; Scardapane and Cardinali, 1977; Schendzielorz et al., 2011; Serova et al., 2002). In addition, $E_{2}$ increases mRNA levels and activity of $\mathrm{TH}$ and $\mathrm{TRH}$, the major rate limiting enzymes in catecholamines and indoleamines biosynthesis, respectively (Babu and Vijayan, 1984; Chaube and Joy, 2011; Rahman and Thomas, 2013; Serova et al., 2002; Donner and Handa, 2009; Aggarwal et al., 2012; Hiroi et al., 2006). Alternatively, it decreases MAO mRNA levels (Aggarwal et al., 2012). Interestingly, although COMT activity is considerably resistant to TMX and $\mathrm{E}_{2}$ effects, $\mathrm{E}_{2}$ decreases COMT protein levels in prefrontal cortex and TMX increases them (Schendzielorz et al., 2011). These previous data are consistent with the amitraz effects we observed on these enzymes and the monoaminergic neurotransmitters. However, we cannot rule out the possibility that amitraz acts by altering 
A

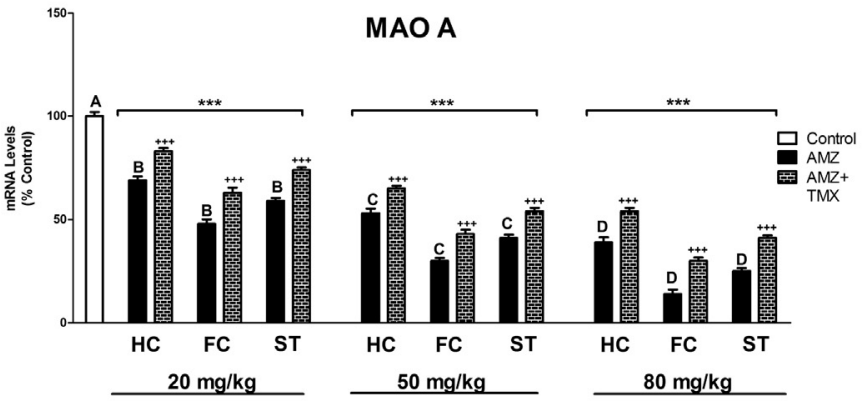

AMZ concentratios

C

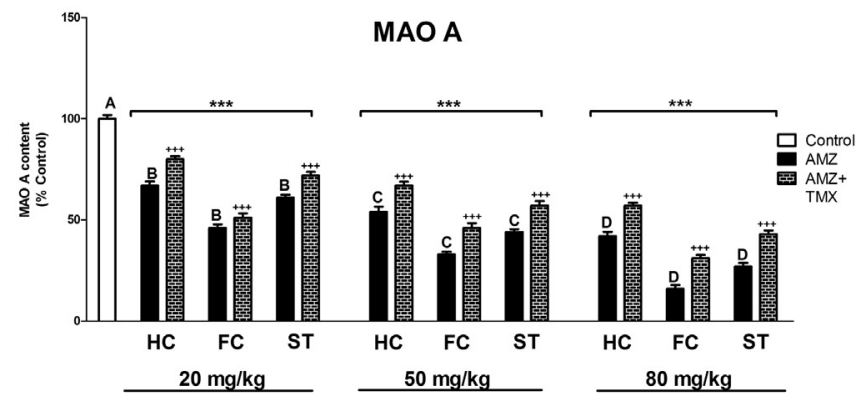

AMZ concentratios
B

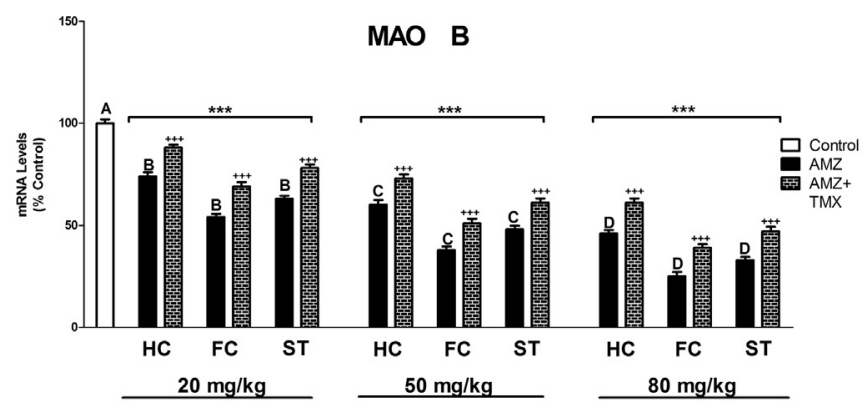

AMZ concentratios

D

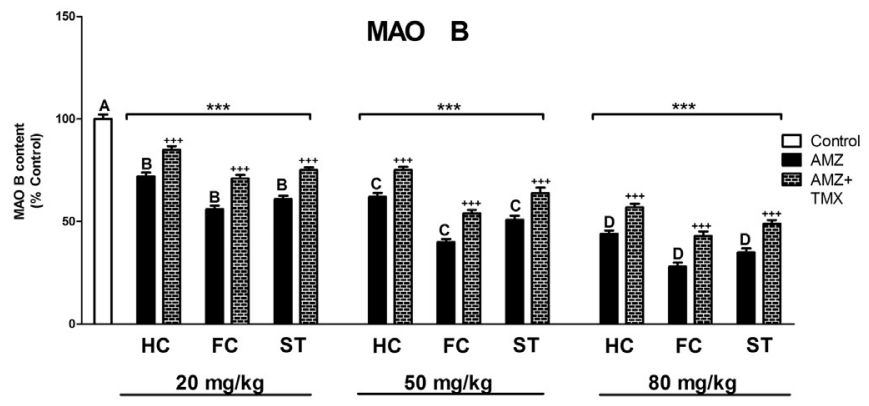

AMZ concentratios

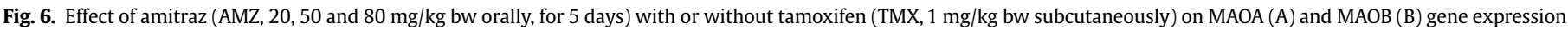

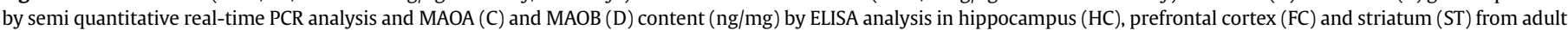

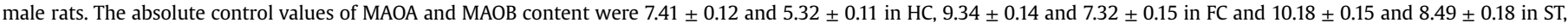

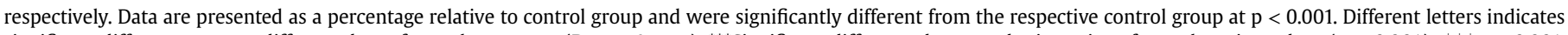

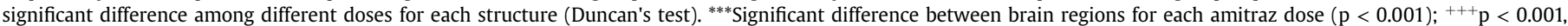
significantly different compared to each amitraz dose.

monoaminergic neurotransmitters transporters, which have been shown to be regulated by $E_{2}$ (Le Saux and Di Paolo, 2006; Meyers and Kritzer, 2009; Rivera et al., 2009; Yu et al., 2009).

The reversion induced by TMX co-treatment on amitraz effects in these enzymes was not complete, suggesting that, besides $E_{2}$ dysregulation, other mechanisms could be involved in these effects. Amitraz's $\alpha_{2}$-adrenergic receptor agonist action has been suggested to be one of the main mechanisms of its neurotoxic effects (Costa et al., 1989; Hsu and Lu, 1984; Hsu and Kakuk, 1984; Yilmaz and Yildizdas, 2003), possibly contributing to the observed effects. In this regard, TH activity and NE release have been described to be regulated by $\alpha_{2}$-adrenergic receptor (Fornai et al., 1995; Owesson et al., 2003). Moreover, it was reported that amitraz inhibits insulin release through $\alpha_{2}$-adrenergic receptors action (Chen and Hsu, 1994) leading to hyperglycemia and glycosuria, a persistent effect observed in most cases of amitraz poisoning (Proudfoot, 2003; Yilmaz and Yildizdas, 2003). Synthesis and re-uptake of NE, DA and 5-HT in the CNS have also been reported to be physiologically regulated by insulin (Figlewicz et al., 1996; Herrera et al., 2005). Besides, experimentally induced hyperglycemia has been reported to produce a significant increase in the catecholamine levels in different areas of the brain (Ramakrishnan et al., 2003). In addition, hypoinsulinemia and hyperglycemia have been shown to alter COMT, BDH and TH activities, which could explain the monoaminergic dysregulation observed (Gupta et al., 1992; Muñoz et al., 1984; Wang et al., 2002). Thus, amitraz's $\alpha_{2}$-adrenergic receptors action could contribute either directly or indirectly, through insulin dysregulation, to the observed effects on monoaminergic neurotransmitters.

Amitraz alters other hormones such as prostaglandin $E_{2}$ (Yim et al., 1978). In this regard, the expression of TH has been shown to be regulated by prostaglandin $\mathrm{E}_{2}$ in vitro (Kim et al., 1996). In addition, histamine $\mathrm{H}_{1}$ receptor is inhibited by amitraz (Costa et al., 1988). In this respect, TH expression and catecholamines synthesis in the brain are modulated by histamine $\mathrm{H}_{1}$ receptor (Moniri and Booth, 2006). Therefore, all the commented mechanisms could also contribute to the effects observed on monoaminergic neurotransmitters.

Affective, cognitive, motor and behavior functions are largely controlled by 5 -HT, NE and DA systems. Thus, amitraz dysregulation of these neurotransmitters could lead to disorders of these functions (Aghajanian and Sanders-Bush, 2002; Antelman and Caggiula, 1977; Somerville et al., 2007; Scholes et al., 2007). Moreover, in addition to its well-documented role in the neural control of reproduction, E2 modulates such neural functions such as affect, anxiety, mood, fear and cognitive function, as well as learning and memory (Jacome et al., 2010). Therefore, the behavioral effects of amitraz including hyperreactivity to external stimuli, aggressiveness, and motor incoordination (Florio et al., 1993) could be mediated by the alterations observed in the enzymes regulating catecholamines and indoleamines synthesis and metabolism. Otherwise, low levels of MAO expression in the brain result in a 
higher predisposition to aggressiveness. In this regard, neurotoxic effect, including increased concentrations of brain NE and 5-HT levels and marked reactive aggressiveness toward intruders have been observed in MAO-A knockout (KO) mice (Godar et al., 2014; Bortolato et al., 2013). Therefore, the aggressiveness induced by amitraz could be related to its MAO gene expression downregulation.

To our knowledge, this is the first work showing that amitraz dysregulates NE, 5-HT and DA neurotransmitter systems by altering biosynthesis and metabolism of these neurotransmitters. Our results are also novel in that they show that amitraz effects on neurotransmitters in male rats can be partially blocked by antagonizing estrogen receptor activities. The amitraz-induced alterations in these neurotransmitter systems may differ between male and female rats due to the differences in sex hormones. However, as the neurotoxic effects described in adult animals after amitraz exposure were not differentiated by gender, these effects may be similar in both genders, but probably with different intensity. Future studies will further characterize mechanisms involved in amitraz alteration of these neurotransmitters systems, the neurotoxic effects mediated by these alterations and the possible sex differences in these neurotoxic effects. These results are of great interest because a better understanding of the underlying mechanisms may inform the development of therapeutic strategies to prevent or treat neurotoxicity induced by amitraz.

\section{Conflict of interest}

The authors declare that they have no conflict of interest.

\section{Acknowledgments}

This work was supported by research grants PR26/20326 from Santander Bank/UCM. The authors would like to thank Sandra L. Petersen, Professor of Neuroendocrinology from University of Massachusetts, for her revision of the present manuscript and Miguel Capo and Margarita Lobo, Professors of Toxicology from the Universidad Complutense de Madrid, for their counseling during the preparation of the present work.

\section{Appendix A. Supplementary data}

Supplementary data related to this article can be found at http:// dx.doi.org/10.1016/j.chemosphere.2017.04.113.

\section{References}

Aggarwal, M., Puri, V., Puri, S., 2012. Effects of estrogen on the serotonergic system and calcitonin gene-related peptide in trigeminal ganglia of rats. Ann. Neurosci. 19 (4), 151-157.

Aghajanian, G.K., Sanders-Bush, E., 2002. Serotonin. In: Davis, K.L., Charney, D., Coyle, J.T., Nemeroff, C.B. (Eds.), Neuropsychopharmacology: the Fifth Generation of Progress. Lippincott-Williams \& Wilkins, Philadelphia (PA), pp. 15-34.

Antelman, S.M., Caggiula, A.R., 1977. Norepinephrine-dopamine interactions and behavior. Science 195, 646-653.

Aziz, S.A., Knowles, C.O., 1973. Inhibition of monoamine oxidase by the pesticide chlordimeform and related compounds. Nature 242, 417-418.

Babu, G.N., Vijayan, E., 1984. Hypothalamic tyrosine hydroxylase activity and plasma gonadotropin and prolactin levels in ovariectomized-steroid treated rats. Brain Res. Bull. 12 (5), 555-558.

Bortolato, M., Godar, S.C., Tambaro, S., Li, F.G., Devoto, P., Coba, M.P., Chen, K., Shih, J.C., 2013. Early postnatal inhibition of serotonin synthesis results in longterm reductions of perseverative behaviors, but not aggression, in MAO Adeficient mice. Neuropharmacology 75, 223-232.

Castelli, M.P., Casti, A., Casu, A., Frau, R., Bortolato, M., Spiga, S., Ennas, M.G., 2013. Regional distribution of $5 \alpha$-reductase type 2 in the adult rat brain: an immunohistochemical analysis. Psychoneuroendocrinology 38 (2), 281-293.

Chapin, D.S., Lookingland, K.J., Moore, K.E., 1986. Effects of LC mobile phase composition on retention times for biogenic amines, and their precursors and metabolites. Curr. Sep. 7, 68-70.
Chaube, R., Joy, K.P., 2011. Estradiol-17 $\beta$ modulates dose-dependently hypothalamic tyrosine hydroxylase activity inhibited by $\alpha$-methylparatyrosine in the catfish Heteropneustes fossilis. Endocrine 40 (3), 394-399.

Chen, T.H., Hsu, W.H., 1994. Inhibition of insulin release by a formamidine pesticide amitraz and its metabolites in a rat beta-cell line: an action mediated by alpha2 adrenoceptors, a GTP-binding protein and a decrease in cyclic AMP. J. Pharmacol. Exp. Ther. 271, 1240-1245.

Chou, C.P., Lu, S.Y., Ueng, T.H., 2008. Modulation of serum concentrations and hepatic metabolism of 17 -estradiol and testosterone by amitraz in rats. Arch. Toxicol. 82 (10), 729-737.

Costa, L.G., Olibet, G., Wu, D., Murphy, S.D., 1988. 2-Adrenoceptor as a target for formamidine pesticides: in vitro and in vivo studies in mice. Toxicol. Appl. Pharmacol. 93, 319-328.

Costa, L.G., Olibet, G., Wu, D.S., Murphy, S.D., 1989. Acute and chronic effects of the pesticide amitraz on alpha 2-adrenoceptors in mouse brain. Toxicol. Lett. 47 135-143.

De Souza Silva, M.A., Mattern, C., Topic, B., Buddenberg, T.E., Huston, J.P., 2009. Dopaminergic and serotonergic activity in neostriatum and nucleus accumbens enhanced by intranasal administration of testosterone. Eur. Neuropsychopharmacol. 19 (1), 53-63.

Del Pino, J., Martínez, M.A., Castellano, V., Ramos, E., Martínez-Larrañaga, M.R., Anadón, A., 2013. Effects of exposure to amitraz on noradrenaline, serotonin and dopamine levels in brain regions of 30 and 60 days old male rats. Toxicology 308, 88-95.

Del Pino, J., Moyano-Cires, P.V., Anadon, M.J., Díaz, M.J., Lobo, M., Capo, M.A. Frejo, M.T., 2015. Molecular mechanisms of amitraz mammalian toxicity: comprehensive review of existing data. Chem. Res. Toxicol. 28 (6), 1073-1094.

Demirel, Y., Yilmaz, A., Gursoy, S., Kaygusuz, K., Mimaroglu, C., 2006. Acute amitraz intoxication: retrospective analysis of 45 cases. Hum. Exp. Toxicol. 25 (10), 613-617.

Directive 2003/65/EC of the European Parliament and of the Council of 22 July 2003 amending Council Directive 86/609/EEC on the approximation of laws, regulations and administrative provisions of the Member States regarding the protection of animals used for experimental and other scientific purposes. Off. J. Eur. Union L 230/32, 16.9.2003.

Donner, N., Handa, R.J., 2009. Estrogen receptor-beta regulates the expression of tryptophan hydroxylase 2 mRNA within serotonergic neurons of the rat dorsal raphe nuclei. Neuroscience 163, 705-718.

Figlewicz, D.P., Brot, M.D., McCall, A.L., Szot, P., 1996. Diabetes causes differential changes in CNS noradrenergic and dopaminergic neurons in the rat: a molecular study. Brain Res. 736 (1-2), 54-60.

Florio, J.C., Sakate, M., Palemo-Neto, J., 1993. Effects of amitraz on motor function. Pharmacol. Toxicol. 73, 109-114.

Fornai, F., Alessandrì, M.G., Fascetti, F., Vaglini, F., Corsini, G.U., 1995. Clonidine suppresses 1-methyl-4-phenyl-1,2,3,6-tetrahydropyridine-induced reductions of striatal dopamine and tyrosine hydroxylase activity in mice. J. Neurochem. 65 (2), 704-709.

Godar, S., Bortolato, C.M., Castelli, M.P., Casti, A., Casu, A., Chen, K., Ennas, M.G., Tambaro, S., Shih, J.C., 2014. The aggression and behavioral abnormalities associated with monoamine oxidase A deficiency are rescued by acute inhibition of serotonin reuptake. J. Psychiatr. Res. 56, 1-9.

Glowinski, J., Iversen, L.L., 1966. Regional studies of catecholamines in the rat brain. I. The disposition of $[3 \mathrm{H}]$ norepinephrine, $[3 \mathrm{H}]$ dopamine and [3H]DOPA in various regions of the brain. J. Neurochem. 13, 655-669.

Grote, K., Andrade, A.J., Wichert Grande, S., Kuriyama, S.N., Talsness, C.E., Appel, K.E., Chahoud, I., 2006. Effects of peripubertal exposure to triphenyltin on female sexual development of the rat. Toxicology $22(1-2), 17-24$.

Gupta, G., Azam, M., Baquer, N.Z., 1992. Effect of experimental diabetes on the catecholamine metabolism in rat brain. J. Neurochem. 58 (1), 95-100.

Handa, R.J., Hejna, G.M., Lorens, S.A., 1997. Androgen inhibits neurotransmitter turnover in the medial prefrontal cortex of the rat following exposure to a novel environment. Brain Res. 751 (1), 131-138.

Herrera, R., Manjarrez, G., Hernandez, J., 2005. Inhibition and kinetic changes of brain tryptophan-5-hydroxylase during insulin-dependent diabetes mellitus in the rat. Nutr. Neurosci. 8 (1), 57-62.

Hiroi, R., McDevitt, R.A., Neumaier, J.F., 2006. Estrogen selectively increases tryptophan hydroxylase-2 mRNA expression in distinct subregions of rat midbrain raphe nucleus: association between gene expression and anxiety behavior in the open field. Biol. Psychiatry 60 (3), 288-295.

Hobler, C., Andrade, A.J., Grande, S.W., Gericke, C., Talsness, C.E., Appel, K.E. Chahoud, I., Grote, K., 2010. Sex-dependent aromatase activity in rat offspring after pre- and postnatal exposure to triphenyltin chloride. Toxicology 276 (3), 198-205.

Hsu, W.H., Kakuk, T.J., 1984. Effect of amitraz and chlordimeform on heart rate and pupil diameter in rats: mediated by alpha 2-adrenoreceptors. Toxicol. Appl. Pharmacol. 73, 411-415.

Hsu, W.H., Lu, Z.X., 1984. Amitraz-induced delay of gastrointestinal transit in mice: mediated by $\alpha 2$-adrenergic receptors. Drug Dev. Res. 4, 655-660.

Ikeda, T., Makino, Y., Yamada, M.K., 2015. 17 $\alpha$-estradiol is generated locally in the male rat brain and can regulate GAD65 expression and anxiety. Neuropharmacology 90, 9-14.

Jacome, L.F., Gautreaux, C., Inagaki, T., Mohan, G., Alves, S., Lubbers, L.S., Luine, V. 2010. Estradiol and ER $\beta$ agonists enhance recognition memory, and DPN, an ER $\beta$ agonist, alters brain monoamines. Neurobiol. Learn Mem. 94 (4), 488-498.

Johnston, C.A., Moore, K.E., 1983. Measurement of 5-hydroxytryptamine synthesis 
and metabolism in selected discrete regions of the rat brain using high performance liquid chromatography and electrochemical detection: pharmacological manipulations. J. Neural Transm. 57, 49-63.

Kato, T., Kuzuya, H., Nagatsu, T., 1974. A simple and sensitive assay for dopamine- $\beta$ hydroxylase activity by dual-wavelength spectrophotometry. Biochem. Med. 10, $320-328$.

Kim, J.S., Chae, H.D., Choi, S.Y., Kim, K.T., 1996. Transcriptional enhancement of tyrosine hydroxylase by prostaglandin E2 in SK-N-BE(2) C cells. Brain Res. Mol. Brain Res. 39 (1-2), 177-184.

Le Saux, M., Di Paolo, T., 2006. Influence of oestrogenic compounds on monoamine transporters in rat striatum. J. Neuroendocrinol. 18 (1), 25-32.

Livak, K.J., Schmittgen, T.D., 2001. Analysis of relative gene expression data using real-time quantitative PCR and the 2(-Delta Delta C(T)) method. Methods 25 , $402-408$.

Lubbers, L.S., Zafian, P.T., Gautreaux, C., Gordon, M., Alves, S.E., Correa, L. Lorrain, D.S., Hickey, G.J., Luine, V., 2010. Estrogen receptor (ER) subtype agonists alter monoamine levels in the female rat brain. J. Steroid Biochem. Mol Biol. 122 (5), 310-317.

Luine, V.N., Khylchevskaya, R.I., McEwen, B.S., 1973. Effect of gonadal steroids on activities of monoamine oxidase and choline acetylase in rat brain. Brain Res. 86, 293-306.

Luine, V.N., Rhodes, J.C., 1983. Gonadal hormone regulation of MAO and other enzymes in hypothalamic areas. Neuroendocrinology 36, 235-241.

Meyers, B., D'Agostino, A., Walker, J., Kritzer, M.F., 2010. Gonadectomy and hormone replacement exert region- and enzyme isoform-specific effects on monoamine oxidase and catechol-0-methyltransferase activity in prefrontal cortex and neostriatum of adult male rats. Neuroscience 165 (3), 850-862.

Meyers, B., Kritzer, M.F., 2009. In vitro binding assays using (3)H nisoxetine and (3) $\mathrm{H}$ WIN 35,428 reveal selective effects of gonadectomy and hormone replacement in adult male rats on norepinephrine but not dopamine transporter sites in the cerebral cortex. Neuroscience 159 (1), 271-282.

Moniri, N.H., Booth, R.G., 2006. Role of PKA and PKC in histamine H1 receptormediated activation of catecholamine neurotransmitter synthesis. Neurosci. Lett. 407 (3), 249-253.

Moser, V.C., Boyes, W.K., MacPhail, R.C., 1987. Investigations of amitraz neurotoxicity in rats. I. Effects on operant performance. Fundam. Appl. Toxicol. 9, 131-143.

Moser, V.C., MacPhail, R., 1989. Investigations of amitraz neurotoxicity in rats. IIl. Effects on motor activity and inhibition of monoamine oxidase. Fundam. Appl. Toxicol. 12 (1), 12-22.

Muñoz, A., Serrano, C., García-Estaño, J., Quesada, T., Miras-Portugal, M.T., 1984 Effect of diabetic hyperglycemia and other sugars on plasma dopamine- $\beta$-hydroxylase activity. Diabetes 33 (12), 1127-1132.

Nathanson, J.A., 1985. Characterization of octopamine-sensitive adenylate cyclase: elucidation of a class of potent and selective octopamine-2 receptor agonists with toxic effects in insects. Proc. Natl. Acad. Sci. U. S. A. 82, 599-603.

Nayebi, A.M., Pourrabi, S., Hossini, S., 2014. Testosterone ameliorates streptozotocininduced memory impairment in male rats. Acta Pharmacol. Sin. 35 (6), $752-757$.

Nissbrandt, H., Engberg, G., Wikstrom, H., Magnusson, T., Carlsson, A., 1988. NSD 1034: an amino acid decarboxylase inhibitor with a stimulatory action on dopamine synthesis not mediated by classical dopamine receptors. Naunyn Schmiedeb. Arch. Pharmacol. 338, 148-161.

Nissinen, E., Männistö, P.T., 1984. Determination of catechol-O-methyltransferase activity by high-performance liquid chromatography with electrochemical detection. Anal. Biochem. 137, 69-73.

Okamoto, M., Hojo, Y., Inoue, K., Matsui, T., Kawato, S., McEwen, B.S., Soya, H., 2012 Mild exercise increases dihydrotestosterone in hippocampus providing evidence for androgenic mediation of neurogenesis. Proc. Natl. Acad. Sci. U. S. A. 109 (32), 13100-13105.

Owesson, C.A., Seif, I., McLaughlin, D.P., Stamford, J.A., 2003. Different alpha(2) adrenoceptor subtypes control noradrenaline release and cell firing in the locus coeruleus of wildtype and monoamine oxidase-A knockout mice. Eur. J. Neurosci. 18 (1), 34-42.

Proudfoot, A.T., 2003. Poisoning with amitraz. Toxicol. Rev. 22 (2), 71-74.

Purves-Tyson, T.D., Handelsman, D.J., Double, K.L., Owens, S.J., Bustamante, S., Weickert, C.S., 2012. Testosterone regulation of sex steroid-related mRNAs and dopamine-related mRNAs in adolescent male rat substantia nigra. BMC Neurosci. $13,95$.

Rahman, M.S., Thomas, P., 2013. Interactive effects of hypoxia with estradiol-17 $\beta$ on tryptophan hydroxylase activity and serotonin levels in the Atlantic croaker hypothalamus. Gen. Comp. Endocrinol. 192, 71-76.

Ramakrishnan, R., Nazer, M.Y., Suthanthirarajan, N., Namasivayam, A., 2003. An experimental analysis of the catecholamines in hyperglycemia and acidosisinduced rat brain. Int. J. Immunopathol. Pharmacol. 16 (3), 233-239.

Reenilä, I., Tuomainen, P., Männistö, P.T., 1995. Improved assay of reaction products to quantitate catechol-O-methyltransferase activity by high-performance liquid chromatography with electrochemical detection. J. Chromatogr. B Biomed. Appl. $663,137-142$.

Rivera, H.M., Oberbeck, D.R., Kwon, B., Houpt, T.A., Eckel, L.A., 2009. Estradiol increases Pet-1 and serotonin transporter mRNA in the midbrain raphe nuclei of ovariectomized rats. Brain Res. 1259, 51-58.

Scardapane, L., Cardinali, D.P., 1977. Effect of estradiol and testosterone on catecholmethyl transferase activity of rat superior cervical ganglion, pineal gland, anterior hypophysis and hypothalamus. J. Neurotrans. 40, 81-86.

Schendzielorz, N., Rysa, A., Reenila, I., Raasmaja, A., Männistö, P.T., 2011. Complex estrogenic regulation of catechol-O-methyltransferase (COMT) in rats. J. Physiolarmacol. 62 (4), 483-490.

Scholes, K.E., Harrison, B.J., O‘Neill, B.V., Leung, S., Croft, R.J., Pipingas, A., Phan, K.L., Nathan, P.J., 2007. Acute serotonin and dopamine depletion improves attentional control: findings from the stroop task. Neuropsychopharmacology 32 (7), 1600-1610.

Serova, L., Rivkin, M., Nakashima, A., Sabban, E.L., 2002. Estradiol stimulates gene expression of norepinephrine biosynthetic enzymes in rat locus coeruleus. Neuroendocrinology 75, 193-200.

Somerville, E.M., Horwood, J.M., Lee, M.D., Kennett, G.A., Clifton, P.G., 2007, 5$\mathrm{HT}(2 \mathrm{C})$ receptor activation inhibits appetitive and consummatory components of feeding and increases brain c-fos immunoreactivity in mice. Eur. J. Neurosci. 25 (10), 3115-3124.

Thiblin, I., Finn, A., Ross, S.B., Stenfors, C., 1999. Increased dopaminergic and 5 hydroxytryptaminergic activities in male rat brain following long-term treatment with anabolic androgenic steroids. Br. J. Pharmacol. 126 (6), 1301-1306.

Veale, D.J., Wium, C.A., Muller, G.J., 2011. Amitraz poisoning in South Africa: a twoyear survey (2008-2009). Clin. Toxicol. (Phila) 49 (1), 40-44.

Wang, J.P., Liu, I.M., Tzeng, T.F., Cheng, J.T., 2002. Decrease in catechol-Omethyltransferase activity in the liver of streptozotocin-induced diabetic rats. Clin. Exp. Pharmacol. Physiol. 29 (5-6), 419-422.

Yilmaz, H.L., Yildizdas, D.R., 2003. Amitraz poisoning, an emerging problem: epidemiology, clinical features, management, and preventive strategies. Arch. Dis. Child. 88 (2), 130-134.

Yim, G.R.W., Holsapple, M.P., Pfister, W.R., Hollingworth, R.M., 1978. Prostaglandin synthesis inhibited by formamidine pesticides. Life Sci. 23, 2509-2516.

Yu, P.L., Wu, C.I., Lee, T.S., Pan, W.H., Wang, P.S., Wang, S.W., 2009. Attenuation of estradiol on the reduction of striatal dopamine by amphetamine in ovariectomized rats. J. Cell. Biochem. 108 (6), 1318-1324.

Zhao, C., Fujinaga, R., Tanaka, M., Yanai, A., Nakahama, K., Shinoda, K., 2007. Region specific expression and sex-steroidal regulation on aromatase and its mRNA in the male rat brain: immunohistochemical and in situ hybridization analyses. J. Comp. Neurol. 500, 557-573.

Zhao, C., Fujinaga, R., Yanai, A., Kokubu, K., Takeshita, Y., Watanabe, Y., Shinoda, K. 2008. Sex-steroidal regulation of aromatase mRNA expression in adult male rat brain: a quantitative non-radioactive in situ hybridization study. Cell Tissue Res. 332 (3), 381-391. 